\title{
Future Logistics: What to Expect, How to Adapt
}

\author{
Henk Zijm ${ }^{1}$ and Matthias Klumpp ${ }^{2}$ \\ 1 University of Twente, Enschede, The Netherlands,w.h.m.zijm@utwente.nl \\ 2 University of Twente, Enschede, The Netherlands and FOM University of Applied \\ Sciences, Essen, Germany, matthias.klumpp@fom.de
}

\begin{abstract}
As a result of global societal and economic as well as technological developments logistics and supply chains face unprecedented challenges. Climate change, the need for more sustainable products and processes, major political changes, the advance of "Industry 4.0" and cyber-physical system are some of the challenges that require radical solutions, but also present major opportunities. The authors argue that logistics has to reinvent itself, not only to address these challenges but also to cope with mass individualization on the one hand while exploiting broad-fielded business applications of artificial intelligence on the other hand. An essential challenge will be to find a compromise between these two developments - in line and in combination with the known triple-bottom line for sustainability - that will define supply chains and logistics concepts of the future.
\end{abstract}

Keywords Trends, Sustainability, Physical Internet, Training, Qualification

\section{Introduction}

Logistics provides the link between subsequent stages of a supply chain, i.e. the entire production and distribution chain from raw materials to final customers for a product or a service, as well as the reverse flow of products, leading to possible re-use of materials or components (closed loop supply chain). Almost always, such a production and distribution chain is not executed by one industry, but instead encompasses a number of separate and distributed companies and organizations jointly operating in a chain or network. This so-called end-to-end supply chain is represented in the Supply Chain Operations Reference (SCOR) model (Simchi-Levi et al., 2008). Current supply chains often span the entire globe and involve production, trade and logistics organizations around the world. In this paper, we review how trade, production and logistics became the global business it is today, and what future developments can be expected (Woxenius and Sjöstedt, 2003). We argue that, faced with today's challenges, a fundamental rethinking of the way we organize production and logistics as well as information management 
and training is needed. To understand this paradigm change, we briefly discuss major, and mutually interconnected, trends, cf. Figure 1.

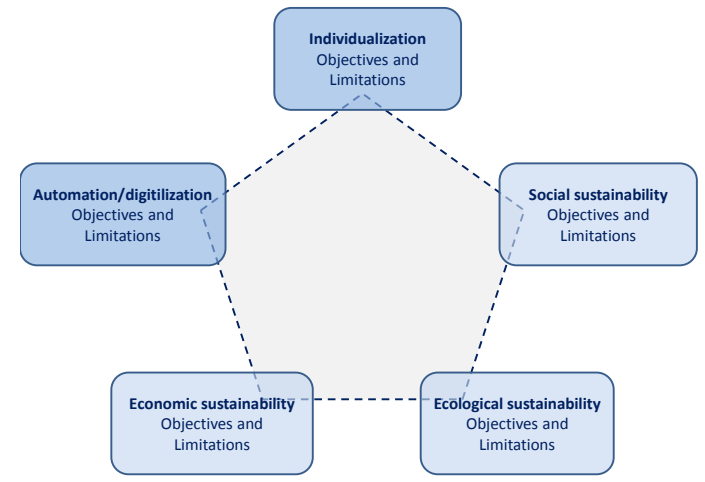

Figure 1: Trend Paradigm - The Five Forces of Future Logistics.

Interconnected with three already well-known and experienced development forces- social, ecological and economic sustainability (people, planet, profit) - we discern two further major trends, i.e. individualization (peer-to-peer, improved customizing, personalized services) and automation/digitilization (artificial intelligence, cyber-physical systems, Internet of Things). These developments are interacting and each is characterized by both objectives and limitations. When the economic objective for example is the reduction of production costs, the limitations are also given in terms of for example minimum wages.

This research contribution which is structured as follows: Section 2 provides a methodological literature review regarding trends and development directions that can be identified in existing research literature. Afterwards, Section 3 outlines the development from past supply chain structures and concepts to modern day structures and predicaments. Technological trends and solutions are the topic of Section 4, whereas Section 5 describes change and adaption processes of training and knowledge management in order to improve logistics in the future.

\section{Literature Review: Logistics Trends}

A large number of articles devoted to theory building, hypothesis testing and exploratory research exist for the field of logistics and supply chain management. In order to outline this evolution we identify trends based on a thorough literature review. While logistics and supply chain management topics are published in a broad array of journals (Fawcett et al., 1995; Grimm et al., 2014), we use academic journals as our source of information. For the analysis the data platform web of science was used in order to retrieve all supply chain management and logistics articles published from 2005 to 2015 , collected with the priority journals on supply 
chain management and logistics as listed by McKinnon (2013). ${ }^{1}$ From these journals, 3,469 articles were identified which served to detect major themes, cf. Table 1.

Table 1. Trend themes in logistics and supply chain management

\begin{tabular}{lll}
\hline Risk management & Sustainability & Coordination \\
\hline Operations management & Green SC/LOG & Collaboration \\
\hline Return logistics & Information technology/industry 4.0 & Cooperation \\
\hline Vehicle routing & Demographic change & Supply chain integration \\
\hline Distribution & $\begin{array}{l}\text { Performance management and meas- } \\
\text { urement }\end{array}$ & Relief/humanitarian operations \\
\hline Purchasing/supply management & Closed loop & Packaging \\
\hline Skills/competences & Human resources & Tracking and tracing \\
\hline $\begin{array}{l}\text { Organizational learning (educa- } \\
\text { tion and training) }\end{array}$ & Inventory/warehouse & Agility/lean/flexibility \\
\hline
\end{tabular}

In order to identify trends, a further analysis was conducted using SAS Enterprise Miner. A list of keywords using the themes from Table 1 was used and the frequency of those in the abstract and title of all articles analyzed. In a third step, the trend themes were grouped into four main research areas: business process management, competitive advantage, strategic management and network structure. The area of business process management deals with management of activities that produce a certain output based on customer demand (Cooper et al., 1997; Davenport, 2003). Furthermore, it provides methods, techniques, and tools to support the design, enactment, management, and analysis of operational business processes (Van der Aalst et al., 2003). The area competitive advantage is a major topic in academia and business practice, including innovative concepts and tools that support organizations to outperform competitors facing major trends. The area strategic management describes the identification and implementation of objectives based on assessments of internal and external factors considering efficient resource allocation. The network structure of the supply chain gives insight in the flow of materials and information from start to end. Furthermore, it shows the value that has been created due to cooperation with partners. Finally, the articles were classified in four time slots (2005-2007, 2008-2010, 2011-2013, 2014-2015, see Table 2).

The analysis reveals some interesting insights. Typically, classical topics such as inventory management, distribution, purchasing and supply management continue to receive high attention. Sustainability however is becoming dominant, not only directly but also in its manifestation through topics such as collaboration and coordination, lean/agile/flexible, and green logistics/supply chains. Information technology is only ranked 15 but this may be due to the fact that a lot of papers on IT in Logistics are not necessarily published in the journals selected by McKinnon (which served as the basis for this search). The shift in time also indicates that sustainability topics have received more attention recently.

\footnotetext{
${ }^{1}$ See Annex for full journal listing.
} 
Table 2. Distribution of trend themes in logistics and supply chain management 2005-2015

\begin{tabular}{|c|c|c|c|c|c|c|c|c|c|c|c|}
\hline \multirow[b]{2}{*}{ Main areas } & \multirow[b]{2}{*}{ Key themes } & \multirow[b]{2}{*}{$\begin{array}{c}2005-2015 \\
\text { (total) }\end{array}$} & \multicolumn{4}{|c|}{ Abstract } & \multicolumn{4}{|c|}{ Title } & \multirow[t]{2}{*}{ Ranking } \\
\hline & & & $\begin{array}{l}\text { 2005- } \\
2007\end{array}$ & $\begin{array}{l}2008- \\
2010\end{array}$ & $\begin{array}{l}2011- \\
2013\end{array}$ & $\begin{array}{l}\text { 2014- } \\
2015\end{array}$ & $\begin{array}{l}2005- \\
2007\end{array}$ & $\begin{array}{l}\text { 2008- } \\
2010\end{array}$ & \begin{tabular}{|l|}
$2011-$ \\
2013
\end{tabular} & $\begin{array}{l}2014- \\
2015\end{array}$ & \\
\hline \multirow{10}{*}{ 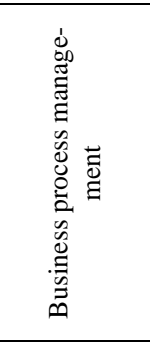 } & Risk management & 79 & 0 & 15 & 33 & 13 & 1 & 4 & 11 & 2 & 9 \\
\hline & Operations management & 28 & 4 & 10 & 6 & 4 & 0 & 2 & 1 & 1 & 18 \\
\hline & Reverse logistics & 62 & 2 & 11 & 13 & 8 & 1 & 10 & 10 & 7 & 14 \\
\hline & Vehicle routing & 73 & 7 & 9 & 16 & 11 & 3 & 7 & 11 & 9 & 13 \\
\hline & Distribution & 415 & 52 & 115 & 105 & 69 & 12 & 31 & 20 & 11 & 2 \\
\hline & Purchasing/supply management & 188 & 16 & 55 & 47 & 23 & 6 & 15 & 14 & 12 & 4 \\
\hline & Relief operations/humanitarian & 53 & 1 & 18 & 8 & 5 & 2 & 11 & 3 & 5 & 16 \\
\hline & Packaging & 15 & 1 & 5 & 3 & 3 & 0 & 1 & 1 & 1 & 19 \\
\hline & Tracking and Tracing & 5 & 1 & 0 & 1 & 1 & 0 & 0 & 1 & 1 & 22 \\
\hline & Inventory/warehouse & 442 & 70 & 108 & 90 & 47 & 18 & 48 & 37 & 24 & 1 \\
\hline \multirow{4}{*}{ 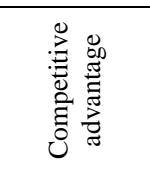 } & Sustainability & 131 & 3 & 16 & 35 & 44 & 2 & 7 & 8 & 16 & 6 \\
\hline & Green SC/LOG & 80 & 0 & 6 & 17 & 21 & 0 & 5 & 12 & 19 & 9 \\
\hline & $\begin{array}{l}\text { Information technology/industry } \\
4.0\end{array}$ & 60 & 6 & 21 & 15 & 7 & 2 & 6 & 2 & 1 & 15 \\
\hline & Demographic change & 4 & 1 & 3 & 0 & 0 & 0 & 0 & 0 & 0 & 23 \\
\hline \multirow{6}{*}{ 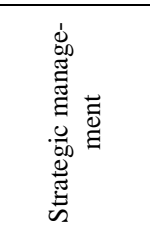 } & $\begin{array}{l}\text { Performance management \& } \\
\text { measurement }\end{array}$ & 50 & 5 & 13 & 11 & 11 & 2 & 3 & 3 & 2 & 17 \\
\hline & Closed loop & 3 & 0 & 0 & 1 & 2 & 0 & 0 & 0 & 0 & 24 \\
\hline & Human resources & 13 & 1 & 6 & 2 & 3 & 0 & 0 & 1 & 0 & 20 \\
\hline & Organizational Learning & 11 & 0 & 3 & 2 & 2 & 0 & 2 & 0 & 2 & 21 \\
\hline & Skills/competences & 75 & 5 & 19 & 27 & 16 & 0 & 3 & 4 & 1 & 11 \\
\hline & Agility/lean/flexibility & 251 & 23 & 68 & 61 & 35 & 10 & 22 & 24 & 8 & 3 \\
\hline \multirow{4}{*}{ 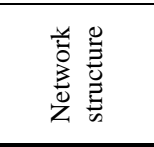 } & Coordination & 104 & 18 & 32 & 24 & 15 & 3 & 7 & 3 & 2 & 7 \\
\hline & Collaboration & 185 & 17 & 41 & 42 & 33 & 8 & 14 & 12 & 18 & 5 \\
\hline & Cooperation & 75 & 11 & 18 & 22 & 12 & 1 & 4 & 4 & 3 & 11 \\
\hline & Supply chain integration & 97 & 7 & 21 & 19 & 17 & 4 & 7 & 13 & 9 & 8 \\
\hline
\end{tabular}




\section{Understanding Logistics: The Historic Development}

In his groundbreaking book "An Inquiry into the Nature and Causes of the Wealth of Nations", Adam Smith developed a first scientific framework on the principles of economic production, starting with the "principle of labor division" (Smith, 1776). This evolved towards the dominant philosophy of efficiency through specialization, worked out towards a first theory on production organizations by Charles Babbage ("On the Economy of Machinery and Manufactures" - Babbage, 1832). The first industrial revolution came along with the invention of the steam engine and its applications in transport and production as engineered by James Watt; it meant the change from the classical domestic manufacturing systems to mass production. This required physical concentration which gave birth to the massive factories that colored the industrial landscape in the $19^{\text {th }}$ and large parts of the $20^{\text {th }}$ century. It was also the time in which early scientific management theories were developed, i.e. by Frederick Winslow Taylor. His work on time and motion studies, best working practices and in particular the differential piece rate system was followed by pioneers such as Frank and Lilian Gilbreth as well as Henry Gantt, who introduced the Gantt chart in project management. A first attempt to systemize quality management was developed by Walter Shewhart through his work at Bell Labs on Statistical Quality Control methods.

Mass production, based on economies of scale, and consequently limited product diversity, continued to dominate industrial production in the first decades after the Second World War. There was a shortage of almost all kinds of goods everything that could be made, could be sold. However, starting with the sixties, as prosperity grew, consumers began to demand variety and differentiation, leading to more complex products. In response, manufacturing industries introduced more versatile machines that could produce a variety of products, albeit at the cost of large setup or changeover times. The result was still production in large batches: economy of scale remained the leading philosophy. Also, the transfer of production to low wage countries in the Far East and Southern America was an attempt to sustain mass production at affordable costs. Efficiency also characterized modern logistics: the introduction of the container and modern material handling systems meant an advantage in processing the growing global transport flows. Functional specialization, concentration of mass production in large factories, the shift of production to low wage countries, and as a result longer supply chains, marked the industrial landscape still in the seventies and eighties.

The two oil crises of 1973 and 1979 for the first time revealed also the weaknesses of the prevalent production philosophy. Raw material prices and interest rates rose sharply and industrial companies started to realize that long supply chains represented large amounts of stock and hence capital invested; besides, long supply chains make it hard to quickly adapt to changing market demands. Companies were inert, and not prepared for the flexibility that a changing society required. In addition, publications such as "Limits to Growth" from the Club of Rome stressed the depletion of natural resources and the pollution of our natural 
environment at an exponentially increasing rate (Meadows et al., 1972). For the first time industry and the public started to realize that current supply chains were to become economically prohibitive, and socially unacceptable.

And so, large scale batch production once applauded as the most efficient production philosophy now became the cause of all evil. Fortunately, new technologies proved to be at least a partial remedy. The introduction of flexible manufacturing systems, often based on computerized (CNC) machining and robotized assembly, helped to balance efficiency and flexibility, not only in production but also in the nodes of logistics networks, i.e. the material handling and distribution centers. In addition, attempts were made to synchronize and integrate supply chains by means of administrative information systems such as MRP and ERP, or by introducing new production philosophies such as Just-in-Time, or lean and agile manufacturing that focus on rigidly removing any buffer stocks as these were primarily seen as indications of waste or slack that characterize non-synchronized production. These were the heydays of the Toyota Production System and of SMED (Single Minute Exchange of Die), an engineering philosophy advocated by Shigeo Shingo, who systematically sought to reduce machine setup or changeover times, thereby again aiming at flexible, synchronized manufacturing and logistics (Shingo, 1985). Hence, although factories became more flexible, long and expensive supply chains due to functional specialization and dispersed production of parts and components continued to be the overarching story. At the same time, these supply chains contribute significantly to the GDP of those countries for which logistics is a strong economic sector, including Germany and The Netherlands (ranking positions 1 and 2 in the World Logistics Performance Indicator 2014, published by the World Bank). The unprecedented growth of production and logistics and its far-reaching rationalization as a result of modern manufacturing methods, the introduction of the container and above all the penetration of automation and computing technologies was definitely one of the sources of prosperity in most developed countries in the last decades.

But this growth came with a price and more and more it is realized that current supply chains are fundamentally unsustainable. Current production and logistics systems cause serious and in the long run unacceptable environmental damage, due to for instance the emission of hazardous materials $\left(\mathrm{CO}_{2}, \mathrm{NO}_{\mathrm{x}}\right.$, particulate matter), congestion, stench, noise and more general the high price that has to be paid in terms of infrastructural load. While the European Committee has set clear targets to reduce Greenhouse Gas Emissions (GGE) in 2050 to $60 \%$ as compared to 1990, the percentage of transport related GGE has increased from $25 \%$ in 1990 to $36 \%$ today (ALICE, 2014). Besides, the pressure of the infrastructure needed on land use gives rise to additional social and environmental problems which hit urban areas in particular.

Current supply chains and logistics systems are global, partly due to natural resources that are scarce and not evenly distributed in terms of type and geographical location but certainly also because of labor rate differences between emerging and mature economies. However, first indications of reshoring production are visible in Europe and America, not only because wage rates are moving upwards in a number of Far-Eastern countries, but also since the amount of manual labor need- 
ed in high tech products continues to diminish, while logistic costs are increasing. As a result, future supply chains are believed to be "glocal": global when needed, local when possible. On the other hand, global supply chains will remain inevitable in cases where conditions for growing food ingredients are only satisfied in some regions in the world, or when minerals are only locally available. They will also continue to exist in cases where material processing consumes such an immense amount of energy that this is only sustainable at places where energy is abundantly and sustainably available, such as locations with geothermic energy, with water-powered energy generation, or with long periods of intense sunshine.

The current world population of 7.2 billion is projected to increase by 1 billion over the next 12 years and reach 9.6 billion by 2050, according to a United Nations report (LOG2020, 2013). Within Europe, population size is predicted to be stable - but a severe shift in population movements is expected from Eastern to Western Europe. Ageing continues, meaning that people in general will work longer in order to maintain a reasonable standard of living. Europe-based companies should be prepared for scarcity of human resources and should be able to provide working conditions that extend the working life of employees. The need to further increase productivity while at the same time diminishing the ecological and social footprint, requires a quality upgrade of the human resource pool, e.g. by better education and training, including lifelong learning programs. In parallel, productivity can be improved by better support tools, easier access to relevant information, and finally further automation of both technical processes (i.e. robotics) and decision making (i.e. artificial intelligence).

Border-crossing supply chains and logistics systems often concern high-value goods, and therefore are vulnerable to crime and illicit acts. Within the European research programs, various projects have developed roadmaps to enhance supply chain safety and security. Regarding safety, extensive attention has been paid to safe working conditions (for instance driving hour regulations) but the fight for supply chain security, abandoning crimes and illegal activities, appears to be a harder one. Economic crimes for example include: theft (robbery, larceny, hijacking, looting, etc.), organized immigration crime (human trafficking, illegal immigration), IPR violations and counterfeiting and customs law violations (tax fraud, prohibited goods). Alternatively, ideologically or politically motivated crimes occur, next to obvious vandalism (Hintsa, 2011). Another aspect of supply chain security is supply chain resilience, which can be defined as the ability to maintain, resume, and restore operations after a major disruption (Gaonkar \& Viswanadham, 2007). Disruptions to supply chains can prove costly: According to research conducted by Accenture, significant supply chain disruptions have been found to cut the share price of impacted companies by $7 \%$ on average (World Economic Forum / Accenture, 2013). Therefore, supply chain risk management is generally seen as one of the major future challenges.

Commercial product life cycles still tend to become even shorter; at the same time an increased re-use of products, components and materials, both via (electronic) second markets and in so-called closed-loop supply chains can be observed (cradle-to-cradle, circular economy). Mass customization is an important aspect of current consumer markets, enabled by fast technological developments. The rapid 
advance of e-commerce is another characteristic of today's markets, with mixed consequences: on the one hand it reduces the number of links in the supply chain, but without adequate regulation of both forward and reverse flows of packages it often leads to a rapid additional increase of urban congestion and pollution. Finally, we mention the concept of a sharing economy, i.e. the notion that customers no longer buy an actual product but only the service the product represents (e.g. cloud computing, music streaming, car sharing). These phenomena will have a profound impact on the ecological footprint of mankind and on design and planning of future supply chains.

\section{What to Expect: Technology and the Future of Supply Chains}

The outlined observations call for a fundamental change when designing futureproof supply chains. Fortunately, both technological and social-economic innovations provide adequate tools that may help to address that challenge.

\section{Technological innovations}

The design of new and lightweight (bio-)materials and their application in a wide variety of products poses new possibilities to diminish both costs and ecological footprints. Another manifestation of improvement through technology is the continuous development of cleaner engines and non-fossil fuel engines (e.g. electric, hybrid or LNG). Technologies such as 3D-printing and additive manufacturing in general are based on material addition, instead of material removal as in classical machining, hence in principle have a waste avoidance potential. Smart packaging also may help to reduce volumes and to avoid waste, in particular in the case of bio-degradable package materials. Modular product design allows the transport of components instead of full products which not only results in a higher package density but in addition allows customization closer to the end-user (Zijm and Douma, 2012). The same holds for 3D printing and micro-machining which are not only a step forward towards mass-customization but in addition have a profound logistics impact, for instance in stimulating "local for local" production. When applied in small batch and one-of-a-kind manufacturing, 3D printing may induce a shift from stock- to order-based production and hence shorter lead times and a reduction of so-called anticipation (safety) stocks.

\section{Automation and Robotics, Internet of Things}

The impact of robotics has already been visible for a long time e.g. in automotive assembly lines but also in warehouses and distribution centers, in so-called AS/RS (Automatic Storage and Retrieval Systems), often consisting of high bay storage racks which are served by fully automated cranes, and equipped with automatic identification, e.g. RFID. Apart from the visible hardware, innovative warehouse management systems help to coordinate and synchronize activities, in close communication with information systems covering both suppliers and customers. Similar developments can be found at container terminal sites in both seaports and inland harbors. Without exception, all such systems rely heavily on smart sensor and 
actuator systems, recently evolving towards the so-called Internet of Things, where devices are equipped with sensors that automatically signal when actions such as ordering or replenishment have to be initiated. Additionally, materials and machinery themselves are able to communicate with each other and find solutions based on decentralized and autonomous decision making using state-of-the-art algorithms. The world of transportation is currently innovating rapidly, as demonstrated for instance by various experiments with freight vehicle platooning, in which a convoy of freight trucks is controlled by a single driver - transportation in 2050 is foreseen to be largely unmanned transportation.

Business Information Systems, new business models

Although many scholars view business information systems and architectures as belonging to the field of technology development, it is essentially more than that. Complex modern supply chains are characterized by the fact that many stakeholders are involved in shaping its ultimate manifestation. These multi-stakeholder and multi-decision maker environments require adequate mechanisms to respond to their requirements, including distributed architectures, cloud computing solutions, cognitive computing and agent-based decision support systems. Organizational innovations are indispensable to fully exploit the potential of advanced information and decision support architectures. The recent attention for data driven models (big data analytics) marks an important further step towards full-blown automated decision architectures. The design and acceptance of decision models based on both horizontal and vertical cooperation in logistics networks however proves to be difficult. Although many stakeholders quickly recognize the potential win-win situation arising from collaboration, they find it in general hard to give up decision autonomy. Mathematically, game-theoretical approaches have proven to provide adequate tools to handle such multi-stakeholder games; for instance the Shapley value calculation defines a "fair" allocation of cooperation gains to single actors. But the key idea that players may give up their individual optimal solution in order to achieve an overall stable equilibrium solution is still hard to accept in particular for private companies that were used to concentrate on their individual profits. This is perhaps the biggest hurdle to be taken to arrive at sustainable logistics; it involves not only smart business solutions but a change of mindset and trust in the value of collaboration.

\section{Circular and sharing economy, servitization}

The key idea behind servitization is the realization that both private consumers and industrial asset owners basically need the functionality of assets and products, rather than the products themselves (Cohen et al., 2006, Neely, 2008). Also, the model of a circular economy is based on the idea that products and systems that are disposed of can be either restored and reused or disassembled after which components and parts are given a second life in next generation equipment. Another option is to jointly use equipment in a predefined group of people (sharing economy). Those products or systems are either owned by individual group members or remain property of the supplier and can be leased or hired at moderate costs. It may be clear that such developments may have important consequences for supply chain design, planning and control in that the focus may at least partial- 
ly switch from delivering products to delivering services. An example is the trend towards car sharing, implying for logistics that cars may not have to be delivered to the individual end customer but towards car sharing operators.

\section{The Physical Internet}

The concept of a "Physical Internet" was initially proposed by Montreuil (2011) as a radical way to integrate economic, social and ecological goals in a new sustainable logistics framework. The Physical Internet is defined as a logistics system in which modular packages are automatically routed from source to destination through a network of hubs and spokes. Major elements of such a network more or less exist for parcels, pallets, containers and swap bodies. A full-fledged physical internet may be built upon all these elements with the holistic integration of existing elements and concepts as the main challenge. To arrive at such enhanced cooperation levels, shippers, manufacturers, retailers, carriers and other providers of logistics services should take the broader sustainability goals into the economic equation. This requires new ways regarding decision making in the system on financial and market criteria but also on safety, security and environmental aspects. In particular, transnational governance and regulation is needed to achieve such a cultural shift, and to encourage collaboration, coordination and horizontal partnerships. A major challenge is to design a multifaceted decision support system, with distributed automated execution by intelligent agents. Radical business models based on openness and sharing of resources are required; but this level of openness is in contrast with the core of e.g. supply chain security. Therefore, adoption will require radical changes with respect to roles and responsibilities of stakeholders. Achieving such a combination of physical and electronic infrastructure is one step, stimulating LSPs to connect to it is a bigger challenge.

Within the European Technology Platform for Logistics ALICE (Alliance for Logistics Innovation and Collaboration in Europe) five roadmaps are defined on key logistics innovation areas, together constituting an integral roadmap towards a realisation of the Physical Internet. Figure 2 presents an overview of these five areas and the subsequent milestones that should be met on the way towards a fullfledged Physical Internet realisation in 2050. 


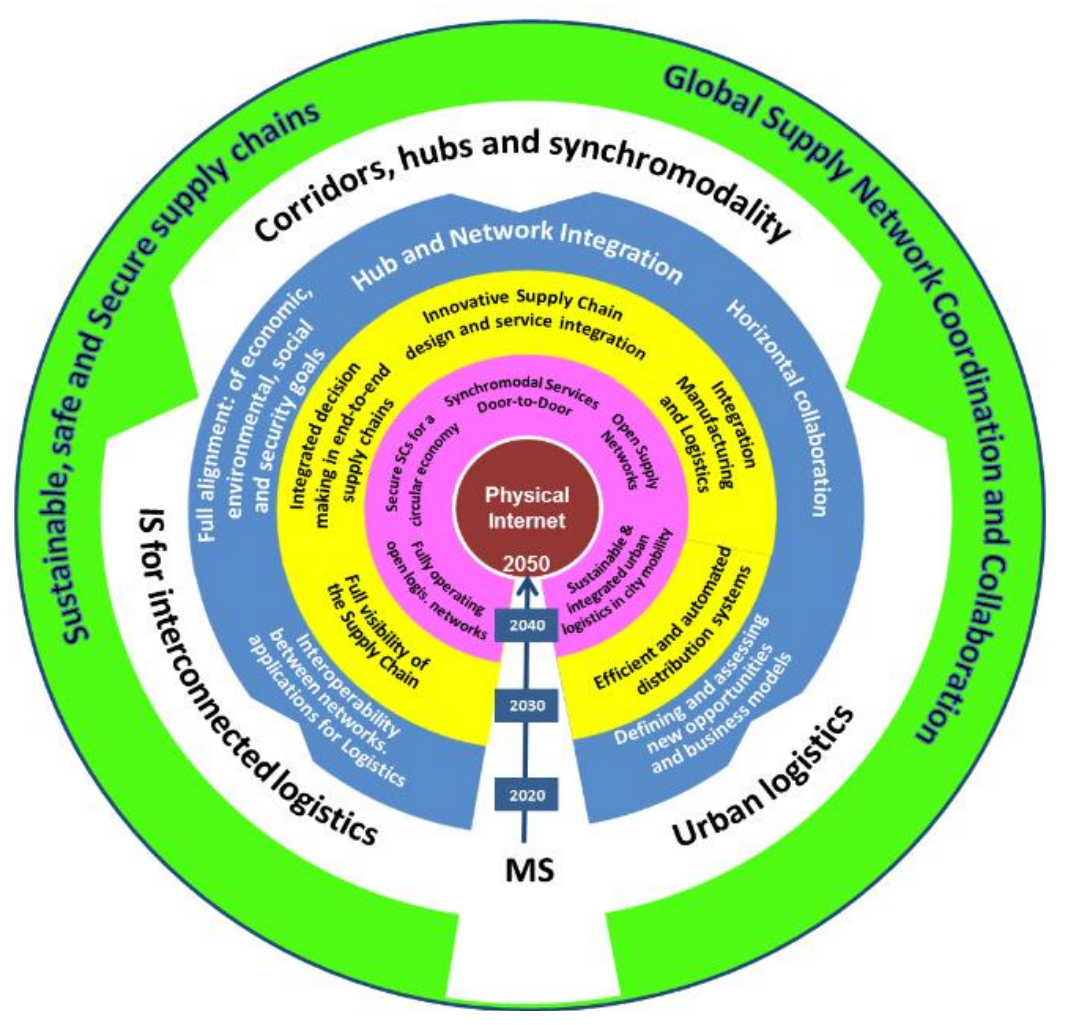

How Figure 2. ALICE roadmap - moving towards the Physical Internet.

\section{How to Adapt: Logistics Training and Knowledge Management}

Technology innovation and smart information systems as expected with the Physical Internet concept heavily depend on the presence of a competent workforce at all levels in both private organizations and government institutions. Training is needed to adopt and adequately apply new technologies while the design of smart business models requires analytical skills to understand the increasing complexities of modern global supply networks. Therefore, apart from natural resources and despite the growing world population, the quality and availability of human competencies appears to be the most important limiting factor ( $\mathrm{Wu}, 2007)$.

Regarding the question of available qualifications and competencies of the human workforce, little is known besides the general recognition that innovation requires a close match between technology, policy as well as business support, and human skills development (i.e. Aghion et al., 2009). Therefore, Figure 3 provides some theoretical thoughts and insights, also regarding automation. 


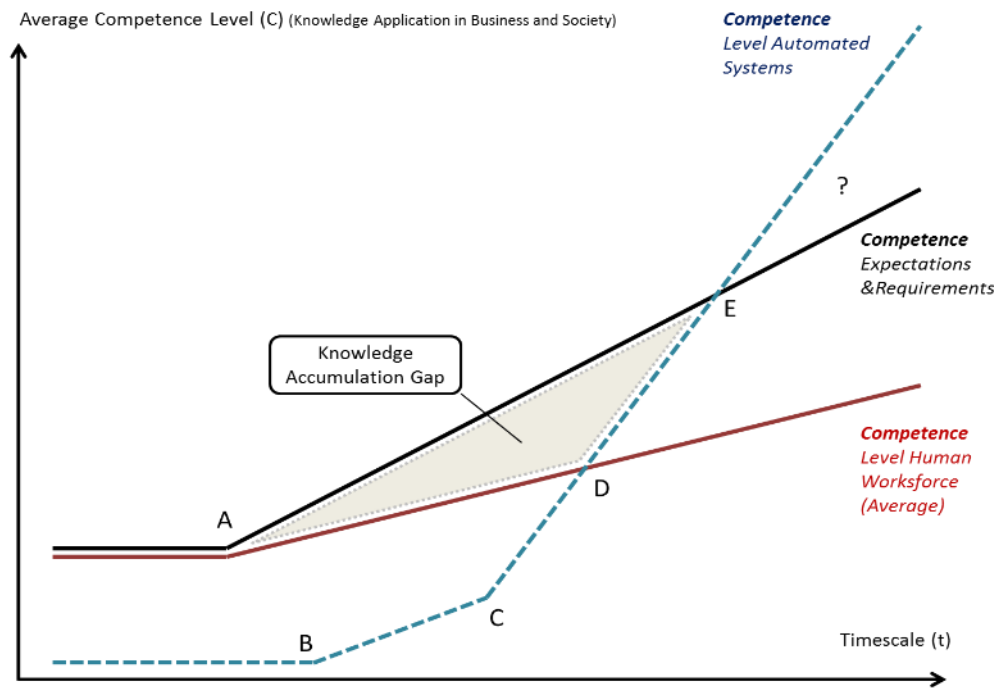

Figure 3. Competence Development for Human Beings and Computers

Starting at about the industrial revolution (point "A"), the necessary or expected competence level of the workforce has increased on average (black line). For logistics processes it can be argued that this still ongoing process has a "double nature": First, existing activities such as truck driving, warehouse processes or production processes increasingly demand higher competence levels - as demonstrated for example by new EU regulations requesting further training of drivers regarding safety, sustainability and hazardous goods as well as technology usage. Whereas only thirty years ago truck driving was a typical "unskilled" profession without any necessary training to do the job properly (apart from a driver's license), today no untrained individual can just start driving in complex transport processes as a multitude of systems (toll systems, routing systems, communication systems, auto ID systems etc.) have to be mastered. This development can be named "knowledge and competence enrichment" of existing processes. Second, new activities arise in logistics and global supply chains, typically with a high competence requirement, such as IT systems management, logistics consulting, logistics and supply chain finance, logistics tender management, logistics controlling. This can be titled "knowledge and competence enlargement" as new processes demand new and higher knowledge levels (Klumpp, 2013).

Between the ever increasing expectations and requirements regarding human competence levels, a "gap" is opening up over time as the required training for humans has for each and every person to start "anew": learning can hardly be "inherited" or automated. Longer schooling and training programs are needed in order to arrive at the required competence levels of a modern logistics and business environment. This can be termed a "knowledge accumulation gap" (grey field) that arises due to the fact that humans are not able to accumulate knowledge over 
generations, as opposed to machines and computers that are increasingly able to do so. Artificial intelligence applications may one day mitigate or close this gap.

Besides human knowledge and competence levels, automated or artificial intelligence (non-human) competence levels (dotted line in Figure 3) are expected to impact technology and business development. Though artificial intelligence had a somewhat "slow start" during the sixties, seventies and eighties of the preceding century (Newell, 1982), it has significantly accelerated in solution contribution width and depth recently. This is connected to the trend of "deep learning", allowing computers autonomously to acquire new knowledge and to find links as well as directions of further learning and meaning themselves (Erhan et al., 2010). As outlined in Figure 3 (point "B"), automated systems were initially very slowly adopted; examples in logistics include the automated gearbox in trucks, partly automated cranes and warehouse equipment as well as automated communication and transmission devices in logistics management (EDI systems, automated decision protocols). These "separate" and limited systems never really "matched" human competence levels, which is why the dotted line traverses significantly below average human competence levels between $\mathrm{B}$ and $\mathrm{C}$.

In recent years however - symbolized by point "C" in Figure 3 - automated systems have undergone a definite change, partly described by a "merging" or an "integration point" as formerly separate systems now are increasingly coupled and are beginning to interact. For example, state-of-the-art automated warehouses are integrated systems of software (warehouse management systems), hardware (moving goods) and even optimization (error analysis, automated storage optimization, learning and prognosis). This integration tremendously increases the capability of such systems and accelerates their innovation speed.

In some cases artificial intelligence and automated systems are already overtaking human competence levels (point "D"). Regarding truck driving for example, the "intelligent" combination of the "old" automated gearbox with GPS-based navigation systems allows a new truck to actually efficiently downshift before a steep slope of an oncoming mountain street is even visible to the human driver. This form of foresight and decision as well as action is a new capability of automated systems, which has recently reached new levels in freight platooning and automated passenger car driving experiments. The general prediction is that automatically driven vehicles are in the long run safer than those controlled by humans; the main obstacles to their further introduction are of a legal rather than a technical nature.

What comes after point " $\mathrm{D}$ " in Figure 3 can only be hypothesized - but it is not unlikely that a future point "E" lies ahead, where automated systems even exceed the expectations (set by humans) of society and business. This may sound risky, as "unintended and unforeseen behavior" of automated systems may rightly worry humans. But as most technologies, it can easily be argued that risks and opportunities are usually embedded in any development, from the taming of fire to nuclear chain reactions and similar regarding artificial intelligence applications. Just for a short insight, some of an unknown multitude of applications and developments can be listed for the area beyond point "E" indicated with a question mark: 
- Automated production systems may increase output on single workdays (i.e. Monday) due to identified repeating sequences of increased customer demand.

- Automated trucks may for example leave the motorway without a specific order to do so - having information about a jam ahead or even a severe accident in order to make way for emergency operations.

- Automated logistics systems may decide to switch to a different supplier in another country having analysed reports about imminent civil war hostilities or fraud in the current supplier's country.

- Automated warehouse systems may decide to use lowtimes like Fridays to prepare and rearrange storage places of specific products which are in high demand on Mondays to a place with shorter exit ways.

In the light of the described qualification and training developments, the general model of innovation in a partnership of technological development and human qualification and training in implementation has to be scrutinized. In the past, often a sequential model was implemented. This model of technology development, followed by implementation and finally training has a clear structure and also a very distinctive risk mechanism - workers were only trained for technologies already developed and implemented, "lost training" was therefore seldom. But in a modern world, this model is outdated. Current models use a parallel approach for at least part of the timeline, regarding implementation and training experiences as essential input for further technology development ("user involvement" in research and development). In the future it is suggested, that in an environment of largely automated blue and white collar work the innovation process may even take place without any large-scale human training. In such systems, human roles may be limited to technology development as well as general oversight. Artificial intelligence and robotics appliances may take over the innovation process completely by introducing new manufacturing as well as management decision concepts without detailed human training. Such a scenario implies that technology development and implementation are two intertwined and parallel processes - as can be observed already in the smartphone app market today. Whatever it will bring, future logistics education and training (human and non-human) will be of key importance to the success of innovation processes in logistics.

\section{Conclusion}

Technology innovation and smart information systems as expected with the Physical Internet concept heavily depend on the presence of a competent workforce. This brings about a new level of interdependence of technology innovation - as well as new business models based on i.e. e-commerce, cloud computing and Industry 4.0 - and knowledge and competence of logistics and management personnel. In the future, logistics companies may find themselves in the same playing field regarding human resources and knowledge management than internet startups and other high-qualification service providers such as the financial and health industries. As dynamics and changes in supply chains will increase as described, 
also a new form of competence will gain more importance: Not the "hard facts" of stored information and fixed concepts which are taught today may be valuable for business purposes, but more the "soft facts" and competences like adaptability (of the mind - followed by the supply chain), flexibility and creativity may be heralded in the future as the main competences needed by logisticians.

Acknowledgments The research presented in this paper is partly connected to the research project and grant "INTER.LOG II" supported by FOM University of Applied Sciences.

\section{References}

ALICE (2014) European Technology Platform for Logistics, see http://www.etp-logistics.eu/.

Aghion P, David PA, Foray D (2009) Science, technology and innovation for economic growth: Linking policy research and practice in 'STIG Systems'. Research Policy 38:681-693.

Babbage C (1835) On the Economy of Machinery and Manufactures. $4^{\text {th }}$ ed, Charles Knight, London.

Cohen M, Agrawal N, Agrawal V (2006) Winning in the aftermarket. Harvard Business Review 84(5):129-138.

Cooper MC, Lambert DM, Pagh JD (1997) Supply Chain Management: More Than a New Name for Logistics. The International Journal of Logistics Management 8(1):1-14.

Davenport TH, Short JE (2003) Information technology and business process redesign. Operations management: critical perspectives on business and management 1:97.

Erhan D, Bengio Y, Courville A, Manzagol P-A, Vinvent P, Bengio A (2010) Why does unsupervised pre-training help deep learning? The Journal of Machine Learning Research 11(1): 625-660.

Fawcett SE, Vellenga DB, Truitt LJ (1995) An evaluation of logistics and transportation professional. Journal of Business Logistics 16 (1):299

Grimm JH, Hofstetter JS, Sarkis J (2014) Critical factors for sub-supplier management: A sustainable food supply chains perspective. International Journal of Production Economics 152:159-173

Gaonkar RS, Viswanadham N (2007): Analytical Framework for the Management of Risk in Supply Chains. IEEE Transactions on Automation Science and Engineering 4(2):265-273.

Hintsa J (2011) Post-2001 Supply Chain Security - Impacts on the Private Sector. Doctoral Thesis, Chapter 7. HEC University of Lausanne.

Hopp W, Spearman M (2008) Factory Physics: Foundations of Manufacturing Management. 3rd ed., Waveland Press, Inc., Long Grove.

Klumpp M (2013) How to structure logistics education: Industry Qualifications Framework or topical structure? Pawar, K.S., Rogers, H. (eds.): Resilient supply chains in an uncertain environment, ISL 2013 Proceedings, Vienna Nottingham, 895-902.

LOG2020 (2013) Logistics and Supply Chain Management 2020: training for the future. WP2: Positioning Paper. ERASMUS LLL Project ID: 527700-LLP-1-2012-1-NL-ERASMUSEMCR.

Meadows DH, Meadows DL, Randers J, Behrens III WW (1972): The Limits to Growth, Universe Books, New York.

Montreuil B (2011) Towards a Physical Internet: Meeting the Global Logistics Sustainability Grand Challenge. Logistics Research 3(2-3):71-87

Neely A (2008) Exploring the financial consequences of the servitization of manufacturing. Operations Management Research 1(2):103-119.

Newell A (1982) The knowledge level. Artificial Intelligence 18(1): 87-127. 
Shingo S (1985) A Revolution in Manufacturing: The Smed System. Productivity Press, New York.

Simchi-Levi, D., Kaminski, P., Simchi-Levi, E., 2008: Designing and Managing the Supply Chain: Concepts, Strategies and Case Studies. McGraw-Hill International, Boston.

Smith A (1776) An Inquiry into the Nature and Causes of the Wealth of Nations. W. Strahan, London.

Van der Aalst, Will MP, Arthur HM Ter Hofstede, and Mathias Weske (2003) Business process management: A survey. Business process management. Springer, Berlin Heidelberg: 1-12.

World Economic Forum / Accenture (2013) Building resilience in Supply Chains. An Initiative of the Risk Response Network In collaboration with Accenture. Geneva.

Woxenius J, Sjöstedt L (2003) Logistics trends and their impact on European combined transport - services, traffic and industrial organization. Log Man 5:25-36.

Wu YC-J (2007) Contemporary logistics education: an international perspective. International Journal of Physical Distribution \& Logistics Management 37(7):504-528.

Zijm H, Douma A (2012) Logistics: more than transport. In Weijers S, Dullaert W (eds.) Proceedings of the 2012 Freight Logistics Seminar. Venlo: 395-404

\section{Annex}

(a) Full Journal Listing (Literature Review)

- International Journal of Logistics Management

- International Journal of Logistics: Research and Applications

- International Journal of Physical Distribution \& Logistics Management

- International Journal of Shipping and Transport Logistics

- Journal of Business Logistics

- Journal of Supply Chain Management

- Logistics Research

- Maritime Economics and Logistics

- Naval Research Logistics

- Supply Chain Management: An International Journal

- Transportation Research E: Logistic and Transportation Review 